\title{
Re-examining our approach to the approval and use of new drugs
}

\section{Shoo K. Lee}

$\infty \quad$ See related article page $\mathrm{I} 843$

I $\mathrm{n}$ this issue, Bellini and colleagues report on a preterm infant who experienced pulmonary hypertension after receiving L-lysine ibuprofen therapy for patent ductus arteriosus. ${ }^{1}$ Their case report is yet another reminder that therapies can have unforeseen adverse reactions, and it also highlights the importance of continued surveillance after a new therapy or technology is introduced. Rare adverse reactions are seldom detected by clinical trials, and they are usually only discovered years after the therapy has been adopted as routine care, as the number of patients receiving the drug increases. In many cases, the adverse drug reactions are not severe or life-threatening, and the issue never enters the public domain. Occasionally, however, the effects are highly injurious or life-threatening and patients are harmed, in which case the social, ethical and economic fallout following public disclosure can be severe and long-lasting. The recent Vioxx affair is a case in point. But how common are these adverse drug reactions, and how soon after a new drug is introduced are they usually detected? Lasser and colleagues ${ }^{2}$ recently reported that of 548 new drugs approved by the US Food and Drug Administration (FDA) between 1975 and I999, 56 (I0.2\%) acquired a black box warning and $16(2.9 \%)$ were withdrawn from the market. This translates into a $20 \%$ probability of a new drug acquiring a black box warning or being withdrawn from the market over a 25 -year period. Half of these warnings and withdrawals occurred within 7 years of the drug's introduction, and half of the withdrawals occurred within 2 years. These data show that serious adverse drug reactions occurring after FDA approval are not uncommon and should be a cause for concern.

Lasser and colleagues ${ }^{2}$ point out that there are numerous reasons for the late detection of these adverse drug reactions. Many premarketing clinical drug trials are underpowered to detect adverse drug reactions. ${ }^{3}$ In some cases, approvals have been granted even when adverse drug reactions were detected by premarketing clinical trials; for example, alosetron hydrochloride was reported to be associated with ischemic coli$\rightarrow$ tis. ${ }^{4}$ Follow-up studies are often lacking, and some drug companies fail to conduct postmarketing (Phase IV) studies, which are required when a safety question arises during the preapproval process. Pharmaceutical companies actively promote early use of new drugs and seek to influence physicians' prescribing patterns and patient preferences through direct-toconsumer marketing so that they can rapidly increase sales and change prescribing patterns ahead of competitors..$^{5-7}$ Market-driven concerns about patent life, profitability and investor stock prices provide strong incentives for these behaviours. ${ }^{8}$

So how should doctors, patients and regulatory bodies respond to the problem of adverse drug reactions? First, doctors should avoid using new drugs when older, reliable alternatives are available. Second, patients should be informed of the limited safety data on new drugs and be advised to be alert for possible adverse reactions. Third, labelling for all new drugs should include the approval date and a black box warning about limited safety data. Fourth, possible adverse drug reactions should be reported to a regulatory agency or voluntary body such as MedWatch and the information disseminated to clinicians. Fifth, a surveillance system operated under the auspices of regulatory agencies should be required for all new drugs. Finally, the regulatory threshold for the approval of new drugs should be higher if there are safe and efficacious alternatives already in existence. Given the magnitude of the problem and the danger to public health, it is imperative that these measures be implemented as soon as possible, and that the public be made aware of the dangers associated with using new drugs.

This article has been peer reviewed.

Shoo K. Lee is Professor of Pediatrics and Scientific Director, iCARE, University of Alberta, Edmonton, Alta.

Competing interests: None declared.

\section{REFERENCES}

I. Bellini C, Campone F, Serra G. Pulmonary hypertension following L-lysine ibuprofen therapy in a preterm infant with patent ductus arteriosus. $C M A J$ 2006;I74(I3):I843-4.

2. Lasser KE, Allen PD, Woolhandler SJ, et al. Timing of new black box warnings and withdrawals for prescription medications. JAMA 2002;287:2215-20.

3. Brewer T, Colditz G. Postmarketing surveillance and adverse drug reactions: current perspectives and future needs. JAMA 1999;28r:824-9.

4. Willman D. How a drug policy led to seven deadly drugs. Los Angeles Times 2000 Dec 20;Sect A:I.

5. Peay MY, Peay ER. The role of commercial sources in the adoption of a new drug. Soc Sci Med 1988;26:1183-9.

6. Stross JK. Information sources and clinical decisions. J Gen Intern Med I987;2:155-9.

7. Basara LR. The impact of a direct-to-consumer prescription medication advertising campaign on new prescription volume. Drug InfJ I996;30:715-29.

8. Petersen M. Pushing pills with piles of money: Merck and Pharmacia in arthritis drug battle. New York Times. 2000 Oct 5;Sect C:I.

Correspondence to: Dr. Shoo Lee, 3rd Fl., Environmental Engineering Building, University of Alberta, Edmonton $A B$ T6G 2G2; fax $780492-2145$ 